\title{
Cost Analysis for IoT Based Condition Based Maintenance to Increase Productivity
}

\author{
Dewanti ${ }^{1}$ and Moses Laksono Singgih ${ }^{1}$
}

\begin{abstract}
Condition Based Maintenance (CBM) is one of maintenance method that believed to be the most effective at reduction of cost and number of activities than the other maintenance methods. Degradation monitoring condition is an important things in order to get effective CBM system. The rapid development in information and communication has lead our industrial phase to industry 4.0, where are lot of smart objects can be connected and integrated in one network system, which is called Internet of Things (IoT). IoT facilitates monitoring and controlling to an object, and help maintenance system to monitor, record, and analyze the degradation of the object. Furthermore, with real time monitoring, system could detect and make decision when is maintenance activity should be done with consideration in cost. This research focused in the issue of integration of many smart objects to support CBM activities in cost reduction and IoT decision making with cost minimization as criteria. Cost analysis has been done using Activity Based Costing (ABC) and mathematical model has been constructed for decision making criteria which will be tested with numerical test using the data that gathered from company which applied IoT system. There are three condition which are tested: system without IoT implementation, current system with IoT implementation (auto shutdown when machine stroke reaches 300), and IoT system that consider the degradation condition to shut down. The result shows that IoT based CBM system that consider degradation level will incur optimal number of activities which resulting in fewer cost that the other systems. With fewer activity maintenance than auto-shutdown at 300 strokes, shows that the productivity increase without any delay due to maintenance.
\end{abstract}

Keywords-Maintenance, IoT, Cost Analysis, Decision.

\section{INTRODUCTION}

Condition Based Maintenance (CBM) are one of maintenance strategy that combine reliability model based on data gathered by sensor to get the maintenance model based on the degradation condition. The purposes of CBM are to decrease the activity of preventive maintenance (PM) [1]. If CBM program could be implemented effectively, surely it could reduce maintenance cost by decreasing the quantity of maintenance activity [2]. The other research mentioned that ineffective maintenance activity can used up $33 \%$ from total maintenance cost [3]. In addition, improper maintenance activity could lead to any losses, such as profit, productivity, and delays delivery problem. CBM has purpose to avoid unnecessary maintenance

${ }^{1}$ Dewanti and Moses Laksono Singgih are with Department of Industrial Engineering, Institut Teknologi Sepuluh Nopember, Indonesia. Email: moseslsinggih@ie.its.ac.id. activity by taking action only if the degradation condition reaching in certain point.

CBM needs a good condition monitoring in order to get real time condition of degradation of an object. The emergence of Internet of Things (IoT) and Industry 4.0 can enhance the technology and information system to monitor the degradation condition of an object. New technology such as WSN (Wireless Sensor Network) can facilitate the distribution of data, compute, communicate, and control the system [4]. Specifically, IoT enforce various physical object to change into smart object. Smart object is the object who can identify and address itself, most importantly, it can communicate with another object. In this content, those smart objects could possibly build a cyber-physical system which are used to process the data and participate in decision making [5]. Three things that are main concept in industry 4.0: cyber-physical system, IoT, and virtualization.

Many research have been done with CBM as a topic, such as [6]-[8], and cost analysis in maintenance such as [9], but there is no research that combine cost analysis of IoT based CBM. CBM system should be taking more advantages with IoT technologies which enabling real time condition monitoring and integrate many data related to CBM in order to take decision when maintenance activity is needed. The purposes of this paper is to study the advantage of IoT system as a support facility in CBM system, analyse the cost incurred in IoT based CBM, and decision making which involving the smart object in production floor. This research is done using mathematical modelling which analysed further using numerical analysis.

This paper is organized as follows, section II is literature review that related to the research. Section III is the model development and assumption that related to maintenance and cost. Section IV is numerical example to illustrate the model. Lastly, the discussion and conclusion is drawn from this research.

\section{LiterATURE REVIEW}

\section{A. Industry 4.0}

Industry 4.0 is known as new level of industry to control all chain from the lifecycle of the product. The emergence of industry 4.0 are enforced from divine customer request. Aspects that controlled in this new phase of industry are all of things that relate to the product lifecycle, starting from design phase, product development, customer delivery, and the useful life of the product [10]. 
The basic of industry 4.0 is the availability of information related to a process in real time. It is not a new concept, but an old concept which enriched with sophisticated technology to combine process operational with information and communication. The purpose of industry 4.0 are to control all process by increase efficiency of production process in resulting of good quality product.

\section{B. Internet of Things}

Internet of Things terminology was first stated by Kevin Ashton in 1999 in supply chain topics. Now, this definition expanding to another aspect such as health, utility, transportation, government, etc [11]. Even though the definition of "Things" are changed along with the development of technologies, the main idea of make computer-based information without any human interfere still remain. It is the evolution of internet condition nowadays, which function is not only to download any information from environment and interact with physical world (actuator, control, and command), but also to facilitate information transfer, analysis, application, and communication [12].

Network and spreading connectivity are a must to construct the IoT system. In order to fulfill that, various application or software are needed to support gadget and communication protocol, such as a tiny sensor for gathering data and distribute it to end server. User then can take the advantage of the data to analyze and elaborate the science. With this, IoT needs an integration from mobile device, edge device such as router, and smart hubs [13].

The Infrastructure of IoT creates a support application which needs a connection without obstacles and an ability to identify its component. Application of IoT is comprehensive, starting from simple automation to more sophisticated environment such as smart city and egovernment. Another applications of IoT are: logistic, transportation [14], supply chain [15], navigation management, aviation industry, automation system industry, etc. E-health, e-government, smart building smart-shopping are some of examples of IoT application to ease human social-life. Disaster management, environment control, smart watering, and energy consumption optimization are some of IoT application in environment aspects.

Here some advantages that can be obtained with application of IoT: in health sector, IoT act as a personal health monitoring, patient monitoring condition, and plague spread modelling. In transportation sector, IoT act as infrastructure monitoring, and traffic management. In service sector, IoT act as air pollution monitoring, and energy consumption monitoring [12]. In logistic sector, IoT is used to enhance the efficiency of logistic management or transportation planning [16]. In manufacturing, IoT is used to get visibility and traceability of an object in production floor, and also to know their status in real time [17].

\section{Condition Based Maintenance}

Reliability and continuous operational from an engineering asset is an ideal expectation from asset manager and industrial owner. But those condition and perform of the engineering asset surely decreasing from time. Maintenance process then needed to ensure that the functional and reliability of engineering asset are good enough to be used during the life cycle of the asset. Maintenance elaborate from Corrective Maintenance (CM) to Preventive Maintenance (PM), and then become Condition Based Maintenance. Furthermore, Pro-Active Maintenance will be developed to avoid any failure of the asset [18].

Compared to other maintenance systems, CBM is believed to be the most effective system to avoid excessive and lack of maintenance activities which has already adopted in Engineering Asset Management (EAM). CBM usually consist of two steps, first is detecting and predicting the condition form an asset, and second is optimizing the decision making whether maintenance is necessary or not [19]. And method used in CBM are categorized as model-based, knowledge-based, data-driven, and combination of the three [20].

Condition monitoring of CBM are categorized into online and offline monitoring [21]. Online monitoring performed when the asset is still running, and offline is the opposite. In addition, monitoring condition can be performed continuously or periodically. Continuous monitoring needs special devices to record the condition automatically, such as sensor, etc. There are several limitation if monitoring is done continuously. First, it will be high cost monitoring, and data gathered continuously does not rule out the possibility that noise will be occurred and recorded, making the information less accurate. In the other hand, periodical monitoring is suitable for asset that cannot be monitored continuously, dues to financial matter or failure characteristic of the asset. Condition Monitoring can be performed in an interval time, such as every shift, or every hour. But, the weakness of periodical monitoring is the possibility that there is some data not recorded in the interval time.

Decision making in CBM are the step after monitoring condition is done. It related to detail analysis in order to determine the problem and maintenance action needed. Prognostic maintenance have strong relation with prediction, which specifically to determine the Remaining Useful Life (RUL) from an asset. Because it is a prediction, there will be uncertainty follows

\section{IOT ARCHITECTURE}

Interconnection between all entities is a must from IoT system. A holistic IoT system should ensure a perfect operation from an object. Reliability is very important in designing IoT system. In order to achieve this, design 
focused on what action should be taken when failure happen and its scaleability [13].

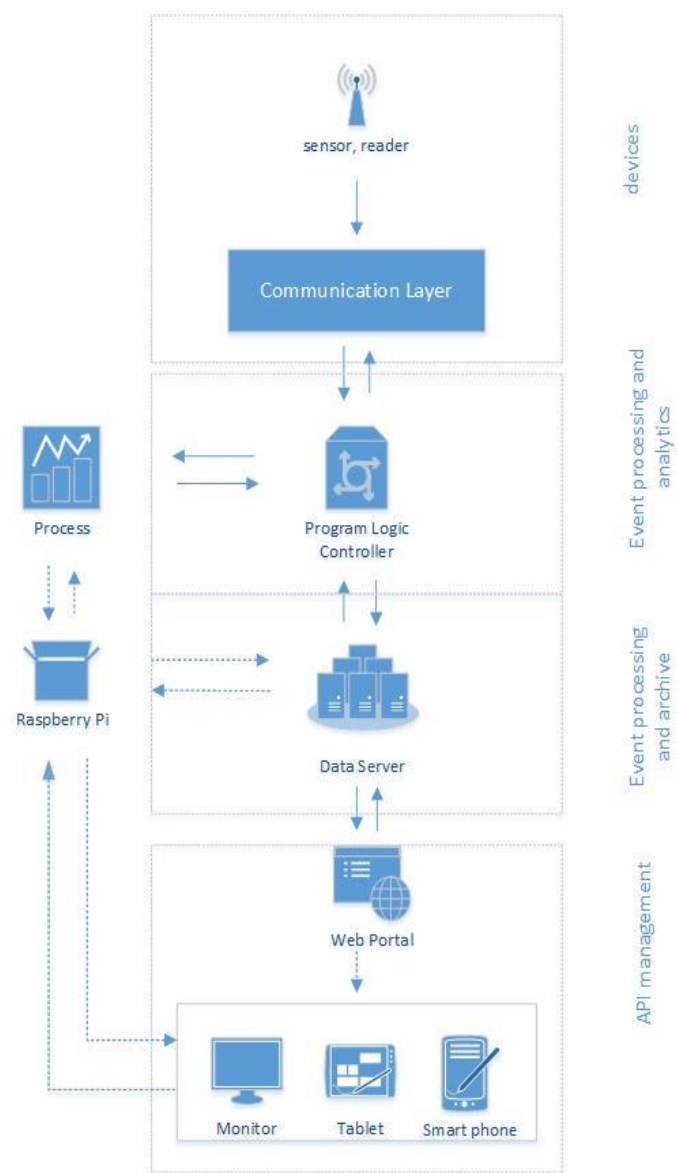

Figure 1. Architecture of IoT in a Manufacturing Company

Figure 1 is an example of IoT system that implemented in manufacturing company, especially in hotpress process. Some entities which connected in one network are the process (degradation condition), and counting system, sensor, web portal, data server, PLC (Program Logic Controller) and user interface. When the process is running, PLC will count the amount of stroke. The stroke data will be stored in data server. Sensor and reader are used to identify what type of product processed and asset number used. The company has policy that the process should be stopped automatically when it reach 300 strokes. 300 is taken from the failure threshold of the most sensitive product. After PLC counts and gets the feedback from data server, PLC will decide whether the process should stop or not. All the status of the asset then can be accessed from user interface such as monitor, tablet or smart phone through web portal.

\section{Model DeVelopment AND Assumption}

\section{A. General Assumptions}

A single unit with degradation condition at time $\mathrm{t}$ stated as random variable $\mathrm{X}_{\mathrm{t}}$. This random variable stand for degradation such as cracking or wearing. The degradation process are following gamma distribution, which is monotonically increasing or non-negative degradation. The system is failed if the variable is greater than $\mathrm{L}$. $\mathrm{L}$ is failure threshold, and expected not to be exceeded for financial reasons. Assumed that:

1) The system inspection performed in discrete time, and

2) The system's failure is self-announcing.

\section{B. Deterioriation Modelling}

Gamma has a characteristic that monotone increasing, and represent clearly with common deteriorating processes. The paths are discontinuous and act as an accumulation from a lot of small shocks. Gamma process has following equation for probability density (pdf) with shape parameter $\alpha$ and scale parameter $\beta$ :

$$
f_{x(t)}(\alpha ; \beta, x)=\frac{\beta^{\alpha} x^{\alpha-1}}{\mathrm{r}(\alpha)} \exp (-\beta x)
$$

$\alpha$ is a positive real number.

\section{RUL Determination}

RUL estimation is used to estimate remaining useful life from a system before it fails with certain probability. $T_{f}$ is where the system is failure, and the reliability of the system is stated as:

$$
R(t)=\mathrm{P}\left(T_{f}>t\right)=\mathrm{P}(X(t)<L)=\int_{0}^{L} f_{\alpha \mathrm{t}, \beta}(x) d x
$$

If at $\mathrm{t}$ the system still functioning, then RUL of a system with probability failure of $\mathrm{q}$ is stated as:

$$
\begin{aligned}
R U L(t, q)=\sup \{v: \mathrm{P}[X(t+v) \geq L \mid X(t)] \leq q\}, & \\
\mathrm{P}[X(t+v) \geq L \mid X(t)] & =\mathrm{P}(X(t+v)-X(t) \\
& \geq L-X(t)) \\
=\int_{L-X(t)}^{\infty} f_{\alpha v, \beta}(x) d x & =1-\int_{0}^{L-X(t)} f_{\alpha v, \beta}(x) d x
\end{aligned}
$$

where $v$ is an increment of degradation.

\section{Cost Analysis}

Cost analysis is done to three condition of system:

(i) System without IoT;

(ii) System with IoT (maximum 300 strokes); which are current condition in the system

(iii) System with IoT modification; with additional analysis to predict failure threshold.

Before the implementation of IoT, the system is using Corrective Maintenance for its repairing system. The cost incurred in non-IoT system are

$$
\boldsymbol{C}=C_{L}+C_{\text {loss }}+C_{r}
$$


By using corrective maintenance, there is possibility that defective product is produced. So, there will be cost for loss material. Loss material will be costly, and so the repairing cost due to maintenance action only performed when the asset is broken.

When installing IoT system, there will be some hardware and software needed to make the system.

TABLE 1.

INVESTMENT NEEDED FOR IOT

\begin{tabular}{cl}
\hline \hline Investment & \multicolumn{1}{c}{ Remarks } \\
\hline Hardware & Operational handphone \\
& Monitor \\
& Digital Measurement \\
& QR code \\
& Router \\
& Raspberry Pi \\
Software & Training \\
& Application \\
\hline \hline
\end{tabular}

Table 1 are some investment needed to make IoT system. Cost incurred in IoT system are

$$
C_{\text {iot }}=C_{r}+C_{L}+C_{m}+C_{s d}+C_{d t b}+C_{r w w}
$$

The equation assumed that there will be no defect product after stopping at 300 stroke and checking the asset. The weakness of this system is the amount of maintenance activity will be increased compared to system without IoT. This will cause new problem in cost. The cost will increase due to operational of maintenance to a good health asset.

With modification of IoT system which is addition of analyze activity, the system expected to have optimal number of maintenance activity. Cost of system will be change into:

$$
\boldsymbol{C}_{\text {iotM }}=C_{r}+C_{L}+C_{m}+C_{s d}+C_{d t b}+C_{a n}
$$

Where,

$C_{r} \quad$ cost due to repairing asset

$C_{\text {loss }} \quad$ cost due to any materials loss (defect, rework)

$C_{L} \quad$ labor cost

$C_{m} \quad$ cost of monitoring condition of process

$C_{s d} \quad$ cost due to automatic shutdown activity

$C_{d t b} \quad$ cost due to database memory

$C_{a n} \quad$ cost for analyze prediction stroke before reaching failure threshold

\section{E. Decision Making Algorithm}

In this research, the maintenance policy is considering degradation condition cost to make decision whether it is needed maintenance action or not. The decision only based on relevant cost that incurred in degradation process. Relevant cost of degradation process can be seen on Table 2.
Assets investigation is conducted in $300^{\text {th }}$ stroke (like the current system). The result is used to identify degradation level of the assets and then determine the amount of strokes remained that allowed to proceed. The prediction amount of stroke can be determined from historical data of the system. When asset's condition is surpassing the internal limit, then asset should undergo repair process. When it hasn't reached internal limit yet, cost analysis is conducted at $\mathrm{T}=\mathrm{i}$ and $\mathrm{T}=\mathrm{i}+\mathrm{n}$ for repairing cost and material loss. $\mathrm{i}+\mathrm{n}$ are prediction of amount of stroke allowed. After the cost are known, then system should decide which cost are lesser. Then asset will undergo the repair process. After repair process is done, cycle will starting all over with the latest condition of the asset. When the system is deciding to continue process, there should be an inspection every interval time.

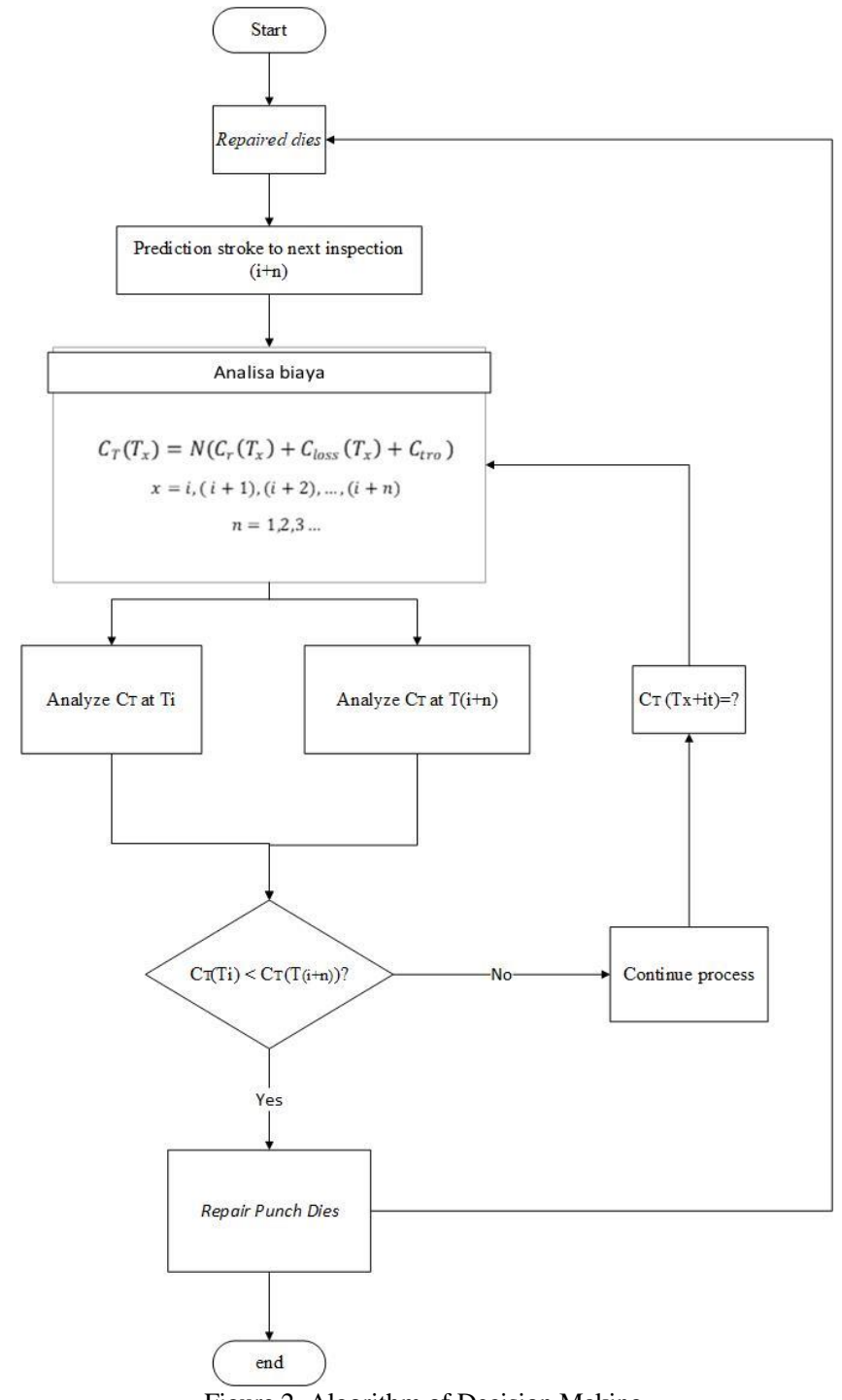

Figure 2. Algorithm of Decision Making 
TABLE 2.

RELEVANT COST

\begin{tabular}{ccccc}
\hline \hline No & Cost classification & Stop Process & Continue Process & Remarks \\
\hline 1 & Labor cost & $C_{L}$ & $C_{L}$ & Irrelevant cot \\
2 & Repair cost & $C_{r}\left(T_{i}\right)$ & $C_{r}\left(T_{i+n}\right)$ & Relevant cost \\
3 & Monitoring cost & $C_{m}$ & $C_{m}$ & Irrelevant cost \\
4 & Cost loss material & $C_{\text {loss }}\left(T_{i}\right)$ & $C_{\text {loss }}\left(T_{i+n}\right)$ & Relevant cost \\
5 & Inspection cost & $C_{i}$ & $C_{i}$ & Irrelevant cost \\
6 & Transportation cost & $C_{t r}$ & $C_{t r}$ & Irrelevant cost \\
\hline \hline
\end{tabular}

TABLE 3.

COMPARISON OF FIXED COST BETWEEN THREE SYSTEMS

\begin{tabular}{|c|c|c|c|c|c|c|c|c|}
\hline \multirow{3}{*}{ No } & \multirow{3}{*}{ Activity } & \multirow{3}{*}{ Pool Rate } & \multicolumn{6}{|c|}{ Activity cost } \\
\hline & & & \multicolumn{2}{|c|}{ Tanpa IoT } & \multicolumn{2}{|c|}{ IoT (300) } & \multicolumn{2}{|r|}{ IoT (M) } \\
\hline & & & Qty & & Qty & & Qty & \\
\hline 1 & Counting stroke & & & & & & & \\
\hline & Labor cost & $2,972.22$ & 1345 & $4,000,000.00$ & 1345 & $4,000,000.00$ & 1345 & $4,000,000.00$ \\
\hline 2 & Condition Monitoring & & & & & & & \\
\hline & Camera monitor & 1159.464 & & & & & 269 & 311895.816 \\
\hline & Barcode read & 78.02 & & & 25 & 1950.5 & 25 & 28986.6 \\
\hline 3 & Automatic shut down & & & & & & & \\
\hline & $\begin{array}{l}\text { Machine counting } \\
\text { System }\end{array}$ & 2782.7133 & & & 1345 & $3,742,749.43$ & 1345 & $3,742,749.43$ \\
\hline 4 & Database & & & & & & & \\
\hline & $\begin{array}{l}\text { Computer } \\
\text { Server }\end{array}$ & $1,500.00$ & & & 6000 & $9,000,000.00$ & 6000 & $9,000,000.00$ \\
\hline 5 & Connectivity & $423,970.00$ & & & 30 & $12,719,100.00$ & 30 & $12,719,100.00$ \\
\hline 6 & Inspection prediction & & & & & & & \\
\hline & Prediction analysis & 800 & & & 5000 & 4000000 & 5000 & 4000000 \\
\hline & TOTAL & & & $4,000,000.00$ & & $33,463,799.93$ & & 33,802,731.85 \\
\hline
\end{tabular}

\section{NUMERICAL EXAMPLE}

Numerical example are based on data gathered from company which implement IoT system in their process. The data is only a reference. From the data gathered, it is know that:

\begin{tabular}{ll}
\hline \hline Labor cost (month) & $4,000,000,-$ \\
Product cost (pcs) & $12,500,-$ \\
Repair cost & $276,667,-$ \\
Breakdown cost & $710,000,-$ \\
Connectivity (year) & $152,629,281,-$ \\
Electricity (kWh) & $3,901,-$ \\
1 month order (pcs) & 60,000 pcs \\
Cycle time (s) & $535 \mathrm{~s}$ \\
\hline \hline
\end{tabular}

It is known that 1 month order for the product is 60000 pieces, and 1 stroke produce 12 pieces of product. Then, to make it easier, cost of all activities converted into cost per stroke. Then we will have fixed cost in a month presented in tabel 3.
Prediction of stroke using RUL estimation and with $\alpha=5$ and $\beta=1$, RUL calculation shown that on the $600^{\text {th }}$ stroke Cumulative Distribution Failure reaches 0.7149435 and on the $700^{\text {th }}$ stroke reaches 0.827 . Then we will take $600^{\text {th }}$ stroke as the internal failure threshold $(75 \%)$. Simulation of cumulative cost are shown in figure 3.

\section{DISCUSSION AND CONCLUSION}

In this work, a cost based decision of condition based maintenance with IoT system is proposed for gamma deteriorating system. The decision related to Remaining Useful Life (RUL) prediction which may be useful for decreasing maintenance activity are considered. Comparing with system without IoT and system with IoT (automatic shutdown after $300^{\text {th }}$ strokes), IoT system resulting in fewer cost and repairing activity. Fixed cost of system with IoT are more costly than system without IoT due to any hardware support, but resulting in significant different in material loss (defect). In addition, there should be 
The $1^{\text {st }}$ International Conference on Business and Management of Technology (IConBMT)

August 3rd 2019, Institut Teknologi Sepuluh Nopember, Surabaya, Indonesia

additional program or software to analyze degradation and cost real time.

This paper still need some more works, such as possibility of the scale and shape parameter might be change after repair asset has conducted, so RUL might be changing in each time inspection result is taken.

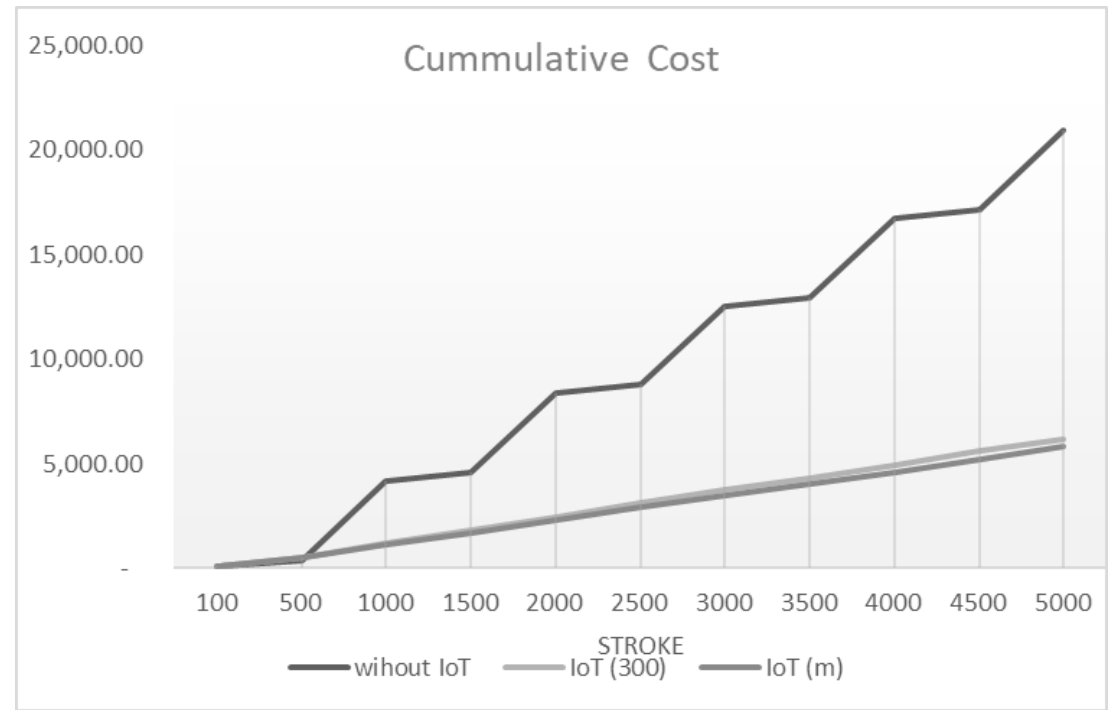

Figure 4. Comparison of Cummulative Cost Between Three System.

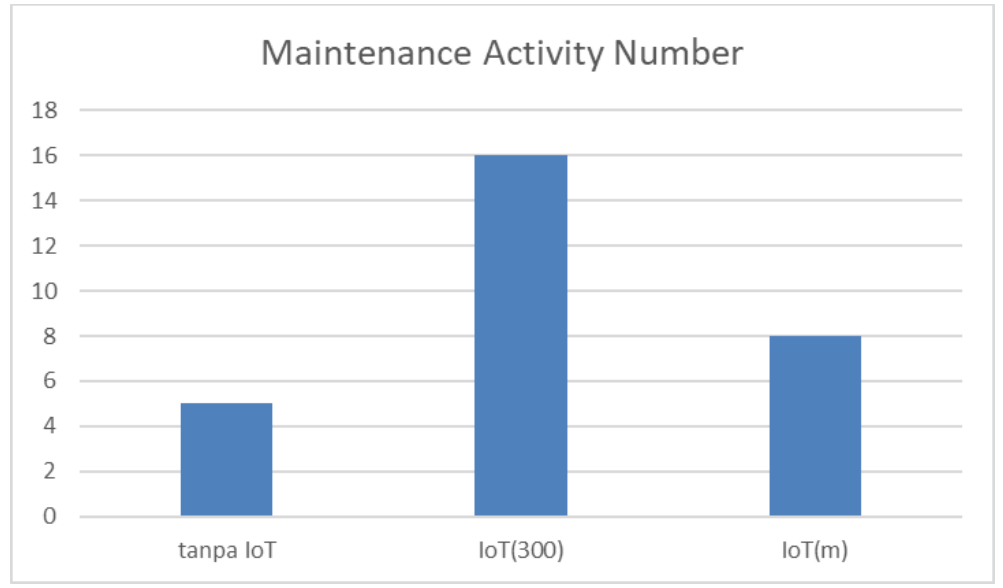

Figure 5. Comparison of Mainteance Activity Number

\section{REFERENCES}

[1] S. Alaswad and Y. Xiang, "A review on condition-based maintenance optimization models for stochastically deteriorating system," Reliab. Eng. Syst. Saf., vol. 157, pp. 5463, 2017.

[2] A. K. S. Jardine, D. Lin, and D. Banjevic, "A review on machinery diagnostics and prognostics implementing conditionbased maintenance," Mechanical Systems and Signal Processing, vol. 20, no. 7. pp. 1483-1510, 2006.

[3] R. K. Mobley, An Introduction to Predictive Maintenance. Burlington: Butterworth-Heinemann Ltd, 2002.

[4] G. Severino, G. D’Urso, M. Scarfato, and G. Toraldo, "The IoT as a tool to combine the scheduling of the irrigation with the geostatistics of the soils," Futur. Gener. Comput. Syst., vol. 82, pp. 268-273, May 2018.

[5] F. Basile, P. Chiacchio, J. Coppola, and D. Gerbasio, "Automated warehouse systems: A cyber-physical system perspective," in IEEE International Conference on Emerging Technologies and Factory Automation, ETFA, 2015.
[6] P. Do, A. Voisin, E. Levrat, and B. Iung, "A proactive condition-based maintenance strategy with both perfect and imperfect maintenance actions," Reliab. Eng. Syst. Saf., vol. 133, pp. 22-32, 2015.

[7] A. Bousdekis, N. Papageorgiou, B. Magoutas, D. Apostolou, and G. Mentzas, "Enabling condition-based maintenance decisions with proactive event-driven computing," Comput. Ind., vol. 100, pp. 173-183, Sep. 2018.

[8] J. Poppe, R. N. Boute, and M. R. Lambrecht, "A hybrid condition-based maintenance policy for continuously monitored components with two degradation thresholds," Eur. J. Oper. Res., vol. 268, no. 2, pp. 515-532, Jul. 2018.

[9] M. Asjad and S. Khan, "Analysis of maintenance cost for an asset using the genetic algorithm," Int. J. Syst. Assur. Eng. Manag., vol. 8, no. 2, pp. 445-457, Jun. 2017.

[10] R. Chitkara and R. Mesirow, The Industrial Internet of Things. 2016.

[11] K. Gusmeroli, S., Haller, S., Harrison, M., Kalaboukas, K., Tomasella, M., Vermesan, O., \& Wouters, Vision and 
challenges for realizing the internet of things, vol. 1, no. APRIL. 2009.

[12] J. Gubbi, R. Buyya, S. Marusic, and M. Palaniswami, "Internet of Things (IoT): A vision, architectural elements, and future directions," Futur. Gener. Comput. Syst., vol. 29, no. 7, pp. $1645-1660,2013$

[13] R. Buyya and A. V. Dastjerdi, Internet of Things: Principles and Paradigms. Cambridge, MA: Elsevier Inc., 2016.

[14] Y. Chen, J. Guo, and X. Hu, "The research of Internet of things' supporting technologies which face the logistics industry," in Proceedings - 2010 International Conference on Computational Intelligence and Security, CIS 2010, 2010, pp. 659-663.

[15] L. W. F. Chaves and C. Decker, "A survey on organic smart labels for the Internet-of-Things," in INSS 2010 - 7th International Conference on Networked Sensing Systems, 2010, pp. 161-164.
[16] H. Lin, R. Zito, and M. Taylor, "A review of travel-time prediction in transport and logistics," East. Asia Soc. Transp., vol. 5, no. March, pp. 1433-1448, 2005.

[17] R. Y. Zhong, X. Xu, and L. Wang, "IoT-enabled smart factory visibility and traceability using laser-scanners," Procedia Manuf., vol. 10, pp. 1-14, 2017.

[18] I. Barnard, "Engineering Asset Management: An Insurance Perspective," Fort Myers, FL, 2009. .

[19] B. Guo, S. Song, A. Ghalambor, and T. R. Lin, "An Introduction to Condition-Based Maintenance," in Offshore Pipelines, Oxford, UK: Elsevier, 2014, pp. 257-297.

[20] A. Bousdekis, B. Magoutas, D. Apostolou, and G. Mentzas, "A proactive decision making framework for condition-based maintenance," Ind. Manag. Data Syst., vol. 115, no. 7, pp. 1225-1250, 2015.

[21] R. Ahmad and S. Kamaruddin, "A review of condition-based maintenance decision-making," Eur. J. Ind. Eng., vol. 6, no. 5, p. 519,2012 